\title{
¿Un amor imposible? Acerca de la traducción de literatura alemana en España durante el siglo $\mathrm{XX}^{1}$
}

\author{
ISABEL HERNÁNDEZ \\ Universidad Complutense de Madrid \\ isabelhg@filol.ucm.es
}

Recibido: 17 de noviembre de 2012

Aceptado: 27 de febrero de 2013

\section{RESUMEN}

La literatura alemana no ha tenido en general la misma aceptación en España que han tenido literaturas de otros países vecinos. Las causas fundamentales que explican esta situación durante la práctica totalidad del siglo XX radican seguramente en el desconocimiento de la lengua y en la falta de traductores verdaderamente especializados, pero también en muchos casos en el desinterés del sistema editorial español.

Palabras clave: traducción literaria, literatura alemana, siglo XX, recepción en España.

\section{An Unrequited Love? Translating German-language Literature in Spain during} the 20th Century

\begin{abstract}
German-language literature has not experienced the same acceptance in Spain that it has been granted in other neighboring countries. The main reason for this lack of interest throughout the $20^{\text {th }}$ century lies most probably in the linguistic barriers and the lack of highly specialized translators, but also in the little interest shown by the Spanish publishing market in literature written in German.
\end{abstract}

1 El título de este trabajo alude directamente al ensayo de Miguel Sáenz que, bajo el título «Geschichte einer unmöglichen Liebe. Die deutsche Literatur in Spanien seit 1945», trazó un primer panorama del recorrido de la literatura alemana en nuestro país durante la segunda mitad del siglo XX. A este trabajo pionero han seguido algunos otros. La presente aportación trata de ordenar estos recorridos incidiendo sobre todo en la evolución del panorama editorial en nuestro país, base indefectible sobre la que se asienta el panorama de la literatura alemana en España. 
Keywords: literary translation, German-language literature, $20^{\text {th }}$ century, reception in Spain.

Sumario: 1. La literatura alemana en España en los inicios del siglo XX. 2. Recepción de literatura alemana durante la dictadura franquista. 3. Apertura del régimen y de la censura. 4. El libro de bolsillo. 5. Nuevas traducciones.

„España es otro mundo. Los Pirineos son una muralla, una frontera para nuestro mundo occidental." "2 Esta afirmación de Max Frisch, escrita en 1951 en su breve ensayo Spanien - Im ersten Eindruck (España... A primera vista), da testimonio de una visión de nuestro país sostenida en numerosas ocasiones y que ha influido de manera decisiva en el proceso de recepción de la literatura alemana en España.

Sobre las relaciones literarias entre ambos contextos culturales hay testimonios más que sobrados, así como los hay también de la vasta huella que la literatura española del Siglo de Oro dejó en las producciones literarias alemanas. Que esta influencia llegara a ser tal se debe, evidentemente, al predominio político y cultural de España en la época, así como al hecho no menos importante de que muchas de las obras que atrajeron la atención de los autores alemanes de aquellos años, se imprimían por aquel entonces en las prensas de los Países Bajos, y no se veían frenadas, por tanto, en esa terrible barrera que desde siempre han supuesto los Pirineos. A pesar de que durante muchos años la imagen de España no fue otra que la de "el país del Lazarillo, la infructuosa patria del alocado Don Quijote, un país pobre, que precisaba de cultura, de comercio y de industria"3 no se puede negar que la influencia de nuestra literatura en las letras alemanas fue grande y contribuyó de manera decidida a la constitución de la prosa alemana, tan atrasada aún en el siglo XVII, así como a la gestación de algunas de las mejores producciones del Romanticismo alemán. Visto esto, cualquiera tendería a pensar que las relaciones literarias continuaron influyéndose durante largo tiempo y que, necesariamente, hubieron de hacerlo en ambas direcciones. Pero la realidad demuestra que esto no ha sido así y que los Pirineos han supuesto siempre una gran barrera para todo lo que trataba de moverse de un lado a otro de ellos, tal como bien supo plasmar Max Frisch en sus impresiones sobre España.

Lo que, en cualquier caso, no deja de resultar sorprendente es el hecho de que la influencia de la literatura española en la alemana llegara a alcanzar un nivel que, efectivamente, no se ha dado en la dirección contraria ${ }^{4}$. Dejando a un lado la barre-

\footnotetext{
2 "Spanien ist eine völlig andere Welt, eine Grenze unsrer abendländischen Heimat." FrISCH, M., «Spanien - Im ersten Eindruck», en: FrISCH, M., Gesammelte Werke 3. Frankfurt: Suhrkamp 1998, 179 ss.

3 FARINELLI, A., «Spanien und die spanische Literatur im Lichte der deutschen Kritik und Poesie II», Zeitschrift für vergleichende Literaturgeschichte NF 5 (1892), 291.

4 Sobre las relaciones literarias y culturales entre ambos países sigue siendo a día de hoy una importante referencia el estudio de Gerhardt HoffmeIster, Spanien und Deutschland. Geschichte und Dokumentation der literarischen Beziehungen. Berlín: Erich Schmidt 1976. Hay traducción española en la Biblioteca Románica-Hispánica de la editorial Gredos.
} 
ra física, cabría preguntarse por qué la influencia alemana no ha llegado nunca a perfilarse con la intensidad de la española. La respuesta no parece demasiado compleja: en primer lugar, la literatura española llegó a alcanzar entre 1580 y 1680 una perfección en todas sus manifestaciones que, unida al marcado sentimiento nacional de aquel Siglo de Oro, se defendió sin problemas ante cualquier influencia exterior; en segundo, la literatura alemana alcanzó su cénit mucho más tarde, de forma que hasta el Romanticismo no contó con una proyección de características semejantes, pero entonces hubo de competir ya con la influencia del resto de literaturas europeas, entre ellas la inglesa, por la que el gusto hispano sintió siempre una gran predilección, y la francesa, cuya presencia en nuestro territorio ha sido prácticamente constante, debido a la hegemonía política y cultural de esta nación durante un amplio periodo de tiempo. Tal hecho podría considerarse también como un tercer motivo para argumentar esta respuesta, puesto que la constante presencia de la literatura francesa en España ha servido de filtro para las producciones que se movían bien en una dirección, bien en otra. Así, toda la literatura alemana que llegó a España a partir de 1700 lo hizo en la práctica totalidad de las ocasiones a través de la traducción francesa de los originales, tal como reza, por ejemplo, el subtítulo de la traducción que el famoso fabulista Tomás de Iriarte hiciera de El nuevo Robinsón (Robinson der Jüngere) de Johann Heinrich Campe (1746-1818): "Historia moral reducida a diálogos. Para instrucción y entretenimiento de niños y jóvenes de ambos sexos, escrita en alemán por el señor Campe. Traducida al inglés, al italiano y al francés, y de éste al castellano, con varias correcciones" "Este procedimiento, que siguió practicándose durante largo tiempo debido al escaso conocimiento que se tenía de la lengua alemana en España, generó en las traducciones de varias décadas los numerosos problemas en la recepción que toda intermediación de una segunda lengua acarrea consigo.

A pesar de este poderoso filtro, traducciones de la lengua original sí las hubo en todos los tiempos, aunque no todas ellas precisamente buenas, otro de los motivos, tal vez, por el que la literatura alemana tiene para el lector medio hispanohablante ese matiz de literatura imposible, tremendamente difícil, y a la que cuesta acercarse. Y así, si la lengua alemana despertaba ya de entrada la sensación de una dificultad y una complejidad tremendas, las traducciones de los textos llevadas a cabo a partir del texto original, contribuyeron a desarrollar aún más este alto grado de complejidad, pues, en muchos casos, la falta de conocimientos de los traductores, cuyo nombre jamás figuró en sitio alguno, buena muestra del poco valor que se le otorgaba a esta labor, resultaba en unas estructuras gramaticales a veces incomprensibles y en un léxico a menudo inabarcable. Durante décadas, los traductores se esforzaron primero por versionar los textos originales para hacerlos más accesibles a un

\footnotetext{
5 A este fenómeno se hace también referencia en los propios textos literarios. Quizá el ejemplo más conocido sea el de uno de los personajes de la conocida novela galdosiana Fortunata y Jacinta (1920), que dice lo siguiente: "Devoró el Fausto y los poemas de Heine, con la particularidad de que la lengua francesa que antes le estorbaba se le hizo pronto fácil”. PÉREz GALdós, B., Obras completas V. Madrid: Aguilar 1950, 1789.
} 
lector hispano, consiguiendo con ello en la mayoría de los casos la pérdida de una buena parte del mensaje original; posteriormente, la conciencia de la falta de calidad de las traducciones llevó a los propios traductores al extremo contrario, esto es, a tratar de mantener la fidelidad al texto alemán a costa de la lengua española, con el consiguiente rechazo por parte del receptor hispano de unos textos casi en su totalidad ininteligibles, situación que se mantuvo hasta bien entrados los años 80 del siglo pasado. Desde entonces, los lectores hispanos cuentan por fin, entre alguna que otra, con un buen número de excelentes traducciones llevadas a cabo por traductores que están contribuyendo a que el panorama literario español se abra cada vez más a una literatura que interesa, pero por la que, de entrada, se manifiesta un rechazo injustificado.

No obstante, y a pesar de los grandes avances realizados, cuando en nuestro entorno se conversa hoy en día sobre la literatura en lengua alemana, y dejando fenómenos como el best-séller El perfume de Patrick Süsskind al margen, surge a menudo la idea generalizada de que el lector hispano la desconoce porque apenas se ha traducido, porque los editores no se interesaban ni se interesan en exceso por un mundo cultural que nos ha quedado siempre un tanto lejano, y cuya lengua y cultura por lo general desconocemos. De que esto no es cierto da buena cuenta el hecho de que en nuestra lengua siempre se han editado estudios sobre la literatura alemana, así como también el de que ya a principios de siglo los españoles contábamos con traducciones de alguna que otra obra de la práctica totalidad de los clásicos alemanes, traducciones que aumentarían notablemente al salir al mercado la colección Universal que empezara a publicar Calpe allá por la segunda década del siglo XX. No deja de resultar llamativo que autores de la categoría de Heinrich Heine, o de Gottfried Keller o Thedor Fontane, dos de los grandes realistas alemanes, prácticamente desconocidos del lector actual, tuvieran ya un espacio en aquella colección, dando testimonio, por un lado, de la actualidad de su obra y, por otro, de la vitalidad del sistema editorial hispano que, ya entonces, recogía entre sus novedades obras de tales autores. No obstante, y sólo por poner un ejemplo, el hecho de que una obra como La gente de Seldwyla de Gottfried Keller no volviera a editarse en nuestro país hasta 1996 y en una edición no completa, dice mucho de la falta de comprensión de que adolece el Realismo alemán en España, sobre todo en estos momentos, en que el Realismo europeo está experimentando en todos los ámbitos una revalorización inusitada.

Para este desconocimiento generalizado (y digo generalizado excluyendo evidentemente a un público claramente intelectual, conocedor sobrado del pensamiento y de las grandes manifestaciones literarias alemanas) se ha acusado durante largo tiempo a la censura que el país ha sufrido durante una buena parte de su historia reciente ${ }^{6}$. Sin embargo, la realidad demostraba que esto no era así, y que, a pesar de

${ }^{6}$ La censura se introdujo formalmente en España el 22 de abril de 1938, aun sin haber concluido el conflicto bélico. Su artífice fue Ramón Serrano Suñer y su objetivo primero suprimir la prensa republicana, convirtiendo al conjunto de la prensa en una institución al servicio del Estado, transmisor de valores oficiales e instrumento de adoctrinamiento político. El 18 de marzo de 1966 se reguló definitivamente a través de la lla- 
no estar permitida la edición de ciertos libros en España, los españoles llegaban a ellos a través de traducciones hechas en diferentes países de Latinoamerica, y también en Francia o la Unión Soviética, a las que se tenía fácil acceso incluso a través de muchos libreros. Que el régimen tenía conciencia de ello lo atestiguan las multas y los cierres de algunas librerías, pero nunca se llegó al extremo de evitar radicalmente la entrada de estos textos en nuestro país.

Incluso en los años más difíciles de la censura, la literatura alemana se editaba y se vendía en España. Los autores más leídos en la década de los 40 y 50 fueron los clásicos: Goethe y Schiller están presentes en todas las editoriales, pero también Chamisso, Eichendorff, Hebbel o Heine, y, curiosamente, igual que en Francia o Italia, son varias las editoriales que publican las novelas de autores contemporáneos como Jakob Wassermann, Ernst Wiechert, Stefan Zweig, Hans Fallada o Thomas Mann (quien, tras haber obtenido el Premio Nobel, adquirió en nuestro país el prestigio con el que sigue contando en la actualidad). También de finales de la década de los 40 data el inicio de la publicación de la revista Diana. Artes Gráficas, en la que, a un precio muy módico, se publicaron los autores más conocidos y también los favoritos del público de la época. En cualquier caso, no es de extrañar que en este momento sean obras que tienen como tema central la guerra las que cuenten con un mayor número de lectores: Estalingrado de Theodor Plivier se publica en 1949, sólo cuatro años después de su aparición en Alemania. En sólo dos años se vendieron en la España de posguerra 154.000 ejemplares, una cifra que, para la época, se corresponde con la de un best-séller actual.

En 1951 comienza la Guerra Fría, hecho que, en pleno de proceso de recuperación, deja a España en una posición internacional de aislamiento, que naturalmente tuvo sus repercusiones en la recepción de la literatura extranjera, y ello a pesar de que durante esa década se permitió cierta liberalidad en la vida universitaria y los estudiantes pudieron tener acceso a textos que hasta entonces estaban prohibidos, a través de las traducciones procedentes de Iberoamérica. Revistas de reciente creación como Ínsula o Índice se abrieron también a la cultura europea. Es precisamente durante la década de los 50 cuando Calpe se funde con Espasa y da comienzo la publicación de la colección de libros de bolsillo que más hizo por la difusión de la literatura y el pensamiento universal entre la población española: en la colección Austral pudo hallar el lector español durante décadas las obras más significativas de la literatura y del pensamiento alemán, desde los grandes clásicos hasta autores menos conocidos, pero no por ello menos relevantes. Esta colección continúa todavía a día de hoy siendo un referente para la literatura universal, aunque durante los últimos años se ha visto superada por la competencia de editoriales como Alianza o Cátedra y ha reducido de manera drástica sus importantísimos fondos, forzada también por la actual situación editorial a la que me referiré más adelante.

mada Ley de Prensa e Imprenta, que introducía considerables modificaciones respecto de la anterior. Esta ley siguió vigente incluso tras la muerte de Franco, hasta que el 1 de abril de 1977 se anuló por Decreto Real. Respecto de la censura en España es muy interesante el estudio de Hans-Jörg NEUSCHÄFER titulado Macht und Ohnmacht der Zensur. Literatur, Theater und Film in Spanien (1933-1976). Suttgart: Metzler 1991. 
Editoriales como Plaza y Janés, entonces aún separadas, comienzan a editar clásicos en bolsillo, una tendencia que se acentuará en décadas venideras al aparecer en el panorama editorial sellos como Planeta o Alianza, o fundirse otros como Plaza y Janés. Los años 60 coinciden con el desarrollo del turismo en nuestro país, gracias a una fuerte propaganda llevada a cabo por el Ministerio de Información y Turismo, curiosamente el mismo que había pasado a encargarse también de la censura. Son éstos los años en los que miles de españoles se ven obligados a emigrar en busca de trabajo a otros países, entre los cuales los de lengua alemana eran destino preferente. Ello conllevó necesariamente una apertura hacia el exterior, así como una normalización en todo lo referente a la vida cultural que permitió la entrada de nuevos autores alemanes en nuestro mercado editorial. Aguilar, que había comenzado ya por los años 50 a publicar las obras más representativas de la literatura universal en volúmenes compilatorios, continúa ahora con esa tarea, publicando también a autores contemporáneos, en el caso alemán, cómo no, a Stefan Zweig y Ernst Wiechert, presentes también en muchas otras editoriales. Se crean también revistas que traen a nuestro país las piezas de teatro más representativas de la escena alemana, un género éste que, tal vez por sus posibilidades subversivas, no había sido traducido en exceso, con excepción, claro está de Goethe y de Schiller. Aguilar publica las piezas de Max Frisch, un autor que a su vez encuentra acogida también en revistas teatrales; Friedrich Dürrenmatt llega primero desde América, pero poco a poco encuentra también su hueco entre los editores españoles, y el teatro de Brecht, aunque no se edita, se lee ya en las numerosas traducciones procedentes de Argentina. Sin que la censura fuera en ese momento un obstáculo para su obra ${ }^{7}$, Max Frisch se convierte en uno de los autores más leídos en esos años gracias a la publicación de sus grandes novelas en la recién fundada editorial Seix Barral, la cual se encargará también de introducir en nuestro país la obra de Heinrich Böll, autor de culto entre diversas generaciones de españoles y del que se ha traducido un mayor número de obras a nuestra lengua: un total de 36, algo poco frecuente en un autor de habla alemana. Durante este periodo tampoco dejaron de llegar ediciones de países iberoamericanos, sobre todo de Argentina, Chile y, un poco más tarde, también de Méjico, país en el que la editorial Porrúa realizó una gran labor de difusión de autores alemanes dentro de su famosa colección "Sepan cuántos...". Fue justo en estos años de expansión editorial cuando los editores españoles, en pleno proceso de expansión, descubrieron entonces el filón que suponía para ellos editar la obra de Hesse. Me detengo un momento en este autor como ejemplo de un fenómeno editorial único por lo que a un escritor de habla alemana se refiere.

Antes de convertirse en un autor de culto, ya las avanzadas editoriales nacidas en la República habían sabido ver en Hesse a un escritor que debía ser conocido por

\footnotetext{
7 “Afortunadamente, la censura española no fue por aquellos años obstáculo alguno para la obra de este autor, que, como escritor escéptico, representaba una repulsa generalizada de las ideologías". FERNÁNDEZ DE Gorostiza, A., «Max Frisch en España», en: Raders, M. / Schilling, M. L., Deutsch-spanische Literaturund Kulturbeziehungen. Rezeptionsgeschichte / Relaciones hispano-alemanas en la literatura y la cultura. Historia de la recepción. Actas de la VII Semana de Estudios Germánicos. Madrid: Ediciones del Orto 1995, 247-256.
} 
el público hispano y así fue como en 1930 Luis López Ballesteros tradujo Demian para la madrileña editorial Cenit, un sello fundado en 1928 que vio truncada su magnífica labor de traducción de literatura extranjera con el estallido de la guerra civil ${ }^{8}$; en 1931 Manuel Manzanares tradujo El lobo estepario para la también madrileña editorial Argis, que lo publicó en una serie denominada "Novelistas nuevos". Aun con todo, ello no significó en absoluto que los editores españoles se interesaran por su obra más allá de estos casos aislados.

De todos es sabido que Hesse fue descubierto en España al serle concedido el Premio Nobel en 1946, pues hasta esa fecha no había vuelto a editarse ni una sola traducción de alguna obra suya. Ese mismo año, sin embargo, estaban ya en el mercado las de El último verano de Klingsor y Siddharta; un año después llegaba en versión de Jesús Ruiz, la de Peter Camenzind, en la Colección Gigante de la editorial barcelonesa Luis de Caralt, que incluía además un prólogo de E.P. de las Heras en el que se informaba al lector sobra la persona y la obra de un autor que era un completo desconocido en nuestro país. Poco a poco fueron apareciendo traducciones de nuevas obras: Narciso y Goldmundo y Bajo la rueda ven la luz en español en 1948; Luis de Caralt edita en 1950 Ensueños, en traducción de Alfonso Pintó, y ese mismo año aparece también la versión española de Gertrudis. Ya se ha mencionado la situación vivida a nivel editorial durante el periodo de la Guerra Fría, con lo que hasta 1961, año en que Aguilar publica en traducción de Mariano S. Luque las Obras Completas en la Serie Biblioteca Premios Nobel, sólo se conocieron el resto de textos de Hesse a través de las traducciones que llegaban desde el otro lado del océano, especialmente desde Argentina y México. Es evidente, pues, que, desde esta situación, Hesse sea en España un autor leído tan sólo en pequeños círculos de intelectuales y de estudiantes, que rápidamente lo asocian, tal como apunta $\mathrm{M}^{\mathrm{a}}$ Luisa Esteve ${ }^{9}$, con los existencialistas, tan de moda en aquellos años.

Es en la década de los 60 cuando, al hilo de las ediciones masivas de libros de bolsillo, empiezan a aparecer en los catálogos de las editoriales más importantes algunos títulos de Hesse de forma regular, pero que continúa siendo un desconocido para el público español lo corrobora el hecho de que en la práctica totalidad de

\footnotetext{
${ }^{8}$ La editorial Cenit fue una de las más importantes del periodo de la República. Creada en una cárcel por Rafael Giménez Siles, Juan Andrade y Graco Marsá, empezó su actividad en 1928. Desde la última etapa del reinado de Alfonso XIII hasta el estallido de la guerra civil, España conoció un gran aumento de la producción y consumo de libros, con la edición de folletos y libros que pasó de 2.000 en 1928 a los casi 4.000 en 1933. Ante la censura creciente sobre las revistas, los empresarios del sector decidieron crear nuevas editoriales revolucionarias, de orientación claramente prosoviética y dedicadas a la lucha de clases. La primera fue Ediciones Oriente, y la siguieron Editorial Cenit, Ediciones Hoy, Ediciones Ulises, Dédalo y C.Y.A.P., entre otras. Eran ediciones no solo comprometidas con la revolución social, sino también con las vanguardias del diseño gráfico. Además de publicar novelas de autores como Benigno Bejarano, Georges Eckmo, Concha Espina o Robert Bouart, también importaron ensayos de los mejores pensadores del momento, como Rosa Luxemburg, Karl Marx, Trotsky o Alexandra Kolontay. Sobre este tema véanse los siguientes estudios: Santonja, G., La República de los libros: el nuevo libro popular de la II República. Madrid: Anthropos 1989; Martínez, J. A., Historia de la edición en España 1836-1936. Madrid: Marcial Pons 2001.

${ }_{9}$ Esteve Montenegro, M. L., «Spanien», en: Pfeifer, M. (ed.), Hermann Hesses weltweite Wirkung. Internationale Rezeptionsgeschichte. Vol. 2. Frankfurt: Suhrkamp 1979, 113-123, aquí 120.
} 
las portadas se añade siempre una mención a su calidad de Premio Nobel, intentando promocionar de este modo las ventas de sus títulos. Por la vía del turismo antes mencionada llegan a España todos los años un buen número de estadounidenses, que se convertirán poco a poco en el referente para la nueva sociedad española, y la juventud, atraída por la contracultura norteamericana, empieza a leer con avidez a un autor cuya defensa de la espontaneidad del individuo frente a las normas coincidía con muchos de los ideales que las nuevas generaciones estaban haciendo suyos. Es precisamente esta espontaneidad, es decir, la ausencia de normas estéticas, de leyes de composición o de rígidas estructuras lingüísticas en primera instancia lo que acerca los textos de Hesse a estos jóvenes lectores; en segunda, el hecho de que el autor siempre fue un individualista al margen de todas las corrientes, capaz de romper los lazos que lo unían a su entorno una y otra vez, y en el que la generación beat encontró la contestación a su pregunta por el camino adecuado en la vida. La respuesta americana a la obra de Hesse vino de la mano de la guerra de Vietnam, de una generación que había vivido en sus carnes la insensatez de un conflicto bélico, la omnipotencia del Estado, la racionalización y la mecanización del mundo, de una generación que quería vivir su vida sin ataduras y que se veía a sí misma como una generación de marginados, que vio en las obras de Hesse la aflicción de su propia alma, de sus problemas, de sus sueños, y que supo ver en él una personalidad que no se acomodaba a los valores burgueses y vivía única y exclusivamente para sí misma. El fenómeno Hesse, por tanto, no deja de ser uno de los más curiosos del siglo XX, pues su revalorización se debió a motivos absolutamente extraliterarios que lo convirtieron en el ídolo de un nuevo movimiento juvenil, que, como él, se rebeló contra las férreas normativas sociales, revolviéndose y protestando contra el hogar paterno y las convenciones en busca siempre de la realización libre de la individualidad en todos y cada uno de nosotros ${ }^{10}$. Así lo manifestaba José María Alfaro en una tercera de $\mathrm{ABC}$ publicada en 1982 con ocasión de un simposio sobre la figura del escritor celebrado en el Goethe Institut de Madrid: "Es muy curioso observar lo acaecido con «Siddharta». Su vasta difusión y popularidad ha sido la consecuencia de un largo viaje. El viaje americano. No es que en su día no obtuviera reconocimientos y aprobaciones. Pero la apoteosis, por decirlo así, de «Siddharta» y, consiguientemente, de su autor, iba a llegar tras su descubrimiento por los adelantados de la «generación beat»y sus hijos, los «hippies» de las ilusiones californianas de alcanzar una seria reforma en los entendimientos de la vida". Así pues, el fenómeno Hesse de seguro no se habría producido de no mediar entre él y los lectores hispanos la lectura norteamericana.

El final de los años 60 trajo consigo uno de los proyectos editoriales más ambiciosos llevados a cabo hasta el momento y gracias al cual aumentó considerablemente la edición en nuestro país de literatura alemana: en 1966 la editorial Alianza da comienzo a la publicación de "El libro de bolsillo", una programación de

10 No deja de llamar la atención el hecho de que Hesse fue interpretado y leído entonces sin atender a características particularmente definitorias de su literatura, como su marcado conservadurismo, lo cual conlleva evidentemente una lectura errónea e interpretaciones falsas de sus textos. 
carácter universal, similar a la llevada a cabo por Austral años antes, pero con traducciones renovadas y con títulos que hasta ese momento no habían podido ser editados en España. Autores como Freud o Kafka son rápidamente colocados junto a Hesse entre aquellos consignados como de obligada lectura. Muchas otras editoriales, como Bruguera, tratarán de emular esta idea con colecciones dirigidas al gran público. A pesar de la mayor oferta de textos alemanes durante estas décadas, la calidad de las traducciones no mejora en exceso; incluso a menudo los textos siguen siendo publicados sin hacer mención expresa de la persona del traductor: no interesa el quién ni el cómo, sino tan sólo que los textos lleguen, tal es la sed de literatura extranjera que se tiene en la España de los años finales de la dictadura. Dada ya la situación casi agonizante del régimen, es normal que este fenómeno de ediciones relativamente masivas se acentúe durante los años 70 , y que ya incluso antes de la muerte de Franco, en 1969, Cuadernos para el Diálogo, en su colección "Libros de teatro", edite una pieza de uno de los escritores más polémicos del siglo: Los plebeyos ensayan la rebelión de Günter Grass. No será, sin embargo, hasta 1973 cuando Barral edite el primer texto en prosa: Anestesia local. La versión española, obra de Carlos Gerhard, llega desde México, donde se había publicado un año antes. La novela que le dio la fama, sin embargo, El tambor de hojalata, no llegaría a nuestro país hasta 1978, diecinueve años después de su edición original. No obstante, ese mismo año se hicieron dos ediciones; la tercera, al año siguiente, un claro indicador de la fama de que gozaba ya este texto, así como de la buena acogida que desde el primer momento se le deparó en nuestro país al posterior Premio Nobel.

A partir de ahí, coincidiendo con el final de la dictadura y la democratización del país, el sistema editorial español, gracias a la creación de nuevos sellos editoriales como Anagrama o Tusquets en 1969, actualizará en buena medida su repertorio de autores alemanes: junto con Grass llegan también traducciones de autores como Elias Canetti, Peter Weiss, Martin Walser, Peter Handke o Thomas Bernhard, todos ellos, a pesar de sus dificultades y de las pocas afinidades de pensamiento que su obra presenta con el mundo hispano, muy apreciados por un determinado sector de lectores. Interesante resulta también el hecho de que la publicación de las obras de estos autores coincidiera con la creación de nuevos sellos editoriales que, dejando a un lado los clásicos, se preocuparon de abastecer el mercado con producciones contemporáneas de altísima calidad. Entre ellos destacan Muchnik, que ha publicado en su totalidad la obra de Elias Canetti, o Alfaguara, que sigue gozando hoy en día de una gran vitalidad. También es el momento en que sellos de alto prestigio en Latinoamérica abren en España sede editorial, como es el caso de Lumen.

No deja de resultar llamativo el hecho de que ya incluso antes de la muerte de Franco empiecen a publicarse también obras de escritores de la República Democrática Alemana. Entre ellos destaca Christa Wolf, cuya novela Noticias sobre Christa T., a pesar de las imposiciones de la censura de su país, consigue ver la luz en español en 1972, tan sólo cuatro años después de la publicación en alemán. El resto de sus obras, curiosamente, no llegaría hasta los años 80 , década en la que verán la luz también las obras de otro autor de la RDA, Christoph Hein, así como el 
gran éxito de la década en el país comunista: Las nuevas cuitas del joven $W$. de Ulrich Plenzdorf.

El fin de la dictadura trajo consigo, pues, una gran apertura a nivel editorial; posteriormente, la entrada de España en la Unión Europea despertó el interés por el aprendizaje de la lengua alemana y, con ella, de su literatura. La década de los 80 fue testigo de un auge inusitado de esta literatura en España, tal como testimonia el Index Translationum de la UNESCO, el cual reúne en 1985 un total de 4.909 obras dentro del apartado de literatura alemana traducida al español frente a las 51 de 1948. Durante esta década siguen naciendo editoriales que integran en sus catálogos a autores de lengua alemana desconocidos hasta entonces para el público hispano. Una de ellas es Siruela, que, fundada en 1982, comenzó su andadura con el proyecto editorial de dar a conocer, en primeras traducciones modernas, las joyas olvidadas de la literatura medieval europea. Un años después inició la tarea de rescatar la literatura fantástica, género poco valorado y apenas conocido por aquel entonces, y en 1989 abrió una colección de literatura contemporánea, a la que seguiría en 2001 la colección "Nuevos tiempos", que da cabida a los nuevos valores de la literatura actual. En todas estas colecciones han tenido siempre un lugar destacado las obras en lengua alemana.

Puedo afirmar sin temor a equivocarme que, en la actualidad, la práctica totalidad de editoriales españolas de prestigio internacional cuentan en sus colecciones con diversos autores alemanes, tanto clásicos como contemporáneos. ¿Qué aspecto presenta, pues, a día de hoy el panorama editorial español por lo que a la literatura alemana se refiere? ¿Podemos seguir hablando de un desinterés por parte de editores y público por la literatura de lengua alemana? ¿Está justificado el desconocimiento en nuestro país de lo que se hace al otro lado de los Pirineos? Si hacemos un repaso de las editoriales más significativas encontraremos, grosso modo, lo siguiente: Espasa Calpe continúa presente en el mercado con su colección Austral a la que, como he mencionado, está sometiendo a un proceso de reestructuración que conlleva, en perjuicio del lector, la desaparición de una buena parte de sus amplísimos fondos debido a la dificultad que, en la actualidad, conlleva para los editores el almacenaje de los mismos. Por lo que a la literatura alemana respecta Austral sigue manteniendo en catálogo a autores tan dispares como Goethe, Hoffmann, Keller, Meyer, Kafka, Rilke o Horváth. Alianza continúa también con la edición de la colección "El libro de bolsillo", dentro de la cual ha empezado a desarrollar colecciones específicas de autores. Por lo que respecta a los alemanes tienen especial significación nombres como los de Goethe, Kafka, Hesse o Hoffmann. A mediados de los años 80 la editorial Cátedra, que contaba ya con la larga tradición de su estupenda colección de "Letras Hispánicas", cuidadas ediciones universitarias con magníficas introducciones llevadas a cabo por especialistas en cada uno de los autores, decide abrir la colección de "Letras Universales", dando cabida en ella a un buen número de autores alemanes, entre los que se cuentan desde escritores medievales como Hartmann von Aue, hasta otros contemporáneos como Thomas Bernhard, pasando por los indiscutibles clásicos. Editoriales como Tusquets, Anagrama, Alfaguara o Siruela mantienen vivo el panorama de los autores contemporáneos. Siruela, fiel al espíritu que la vio nacer, mantiene al día sus espléndidas ediciones de los desconocidos tex- 
tos medievales. Hace también algunos años comenzó a dedicar un espacio a los también desconocidos autores que protagonizaron el intenso cambio del siglo XIX al XX, una época que tiene también en la editorial Acantilado un espacio de primera magnitud, con unos fondos magníficos que han ido viendo la luz a lo largo de la última década. De este modo, autores como Arthur Schnitzler, Stefan Zweig o Joseph Roth están viendo traducida la práctica totalidad de su obra en un sello de una calidad encomiable. Por lo que se refiere a los clásicos, la labor de la editorial Alba merece una mención especial, con sus ediciones destinadas a un público no especializado, y que están logrando alcanzar amplios sectores de la sociedad. Pero no todo queda ahí, sino que incluso alguna editorial como es el caso de minúscula, ha llegado a lanzar, gracias a un esfuerzo loable, una colección dedicada específicamente a la literatura alemana con un nombre más que elocuente: "Alexanderplatz".

Hemos hablado hasta ahora sólo de prosa y teatro. Como género minoritario que es, la lírica tiene también una representación minoritaria entre las traducciones. No obstante, las diversas antologías editadas durante décadas han contribuido a difundir la lírica de autores como Paul Celan, Erich Fried, Else Lasker-Schüler o Nelly Sachs, entre otros. A lo largo de las dos últimas décadas, sin embargo, la labor de editoriales como Hiperión o Visor ha contribuido a difundir entre el público hispano el conjunto de la producción lírica de autores imprescindibles como Heinrich Heine, Bertolt Brecht, Hölderlin o Rilke, e incluso de otros minoritarios como Ingeborg Bachmann.

En cualquier caso, y a pesar de los esfuerzos, la concesión del premio Nobel a dos escritoras de lengua alemana en estos últimos años ha vuelto a poner de manifiesto el desconocimiento que el lector español tiene de la producción literaria en el ámbito germano. De la obra de Elfriede Jelinek, Premio Nobel en 2004, se habían traducido con anterioridad a esa fecha tan sólo tres títulos: Los excluidos en 1992, y El ansia y La pianista en 1993, todos ellos con un reducido número de ventas. De Herta Müller, Premio Nobel en 2009, cuatro: En tierras bajas en 1990, El hombre es un gran faisán en el mundo en 1992, La piel del zorro en 1996 y La bestia del corazón en 1997. Ambas autoras habían sido editadas en España por las editoriales Siruela y Mondadori, conocidas por apostar con frecuencia por los nuevos valores de la literatura occidental.

Pero el valor que demuestran algunas editoriales asumiendo ciertos riesgos al publicar a determinados autores, no es compartido por la mayoría de las que conforman el elenco editorial del país, y en muchos casos, lo que el lector hispano tiene a su disposición es exclusivamente aquello que el editor considera oportuno editar, siguiendo criterios que, en ocasiones, no tienen que ver tanto con la calidad como con el número de posibles ejemplares vendidos, cerrando con ello las puertas a obras de una calidad excelente, que sólo podrán ser descubiertas por el lector hispano si un buen día un editor, respondiendo a un criterio equis, decide publicarlas y son bien acogidas por la prensa especializada. Es lo que ha ocurrido precisamente durante estos dos últimos años con la obra del austriaco Adalbert Stifter, del que Cátedra había publicado ya en 1990 y sin ningún éxito parte de su colección Piedras de colores, y que ahora, a partir de la publicación de su magnífica novela Verano tardío, está convirtiéndose en un autor de culto para muchos lectores. 
Visto, pues, el actual panorama editorial español, si en nuestro país los editores no se atreven a editar todo aquello que les parece arriesgado porque no va a contar de entrada con una aceptación masiva por parte del público, la situación para la literatura alemana no será nunca, debido a sus dificultades de recepción, precisamente la más halagüeña, pues se ve obligada a competir con todo lo procedente de los países anglófonos, de los que se traduce veinte veces más que de los de lengua alemana.

Sin duda, los criterios editoriales son los que más pesan a la hora de decidir y la necesidad de vender a toda costa es algo que se ha generalizado ya desde hace años en un entorno editorial en el que la competencia se ha vuelto feroz y en el que las editoriales pequeñas han proliferado también de una manera espectacular ayudadas por las numerosas subvenciones a la edición y a la traducción que se conceden desde los más diversos ámbitos nacionales e internacionales. Este fenómeno, que podría haber tenido muy buenas consecuencias para el desarrollo y la expansión de otros ámbitos literarios en el nuestro, ha tenido en algunos casos el efecto contrario, pues ha provocado la dispersión editorial de algunos autores, a los que ahora, debido a que ya tienen una o más obras publicadas en otros sellos, las grandes casas editoriales no quieren acoger en sus programas. Estas pequeñas editoriales, por lo general, invierten poco, no consiguen traductores de prestigio y, en consecuencia, viven también poco en un entorno en el que el libro se caracteriza ya por ser un objeto de corta vida en los estantes de las librerías. Así pues, el incremento del volumen de edición que se ha producido en España a lo largo de las dos últimas décadas no da al lector la posibilidad de escoger con tranquilidad ante la abundante oferta, ni permite tampoco que las editoriales mantengan constantemente las obras en catálogo. Y es que, echar un vistazo a las mesas de novedades de las librerías supone perderse entre un sinfín de títulos entre los que, evidentemente, es difícil encontrar el pequeño porcentaje que, entre todo ello, supone la traducción de literatura alemana. Y no porque se traduzca poco, pues, ya lo hemos visto, contamos en España con editoriales que hacen grandes esfuerzos por incluir en sus programas a autores alemanes, a pesar de que en muchos casos se limiten exclusivamente a los más conocidos por el público español y arriesguen poco a la hora de introducir nombres nuevos ante el temor de un fracaso en las ventas. El libro debe tener las ventas aseguradas, venderse de inmediato, y no puede acumularse en librerías ni almacenes con el consiguiente problema de que las obras dejan de estar disponibles en un muy breve espacio de tiempo, llegando a ser imposibles de encontrar. Ello no sólo conlleva el hecho de que los lectores no puedan disfrutar de obras trascendentales para el conocimiento y el acercamiento mutuos, puesto que a menudo ni se percata de ellas, sino también que las obras no lleguen a tener la posibilidad de dejar su huella en las letras españolas, como fuera el caso en décadas anteriores, sobre todo en el ámbito del teatro o la lírica. Ello explicaría tal vez, a pesar de la gran labor realizada, el fenómeno incomprensible de que autores de la categoría de Adolf Muschg o Siegfried Lenz, por referirme únicamente a dos escritores contemporáneos, sigan siendo unos desconocidos en nuestro entorno.

Es probable que en este recorrido por un siglo de traducciones en España me haya dejado en el tintero a más de un editor que, sin duda, ha contribuido a aumentar la presencia de la literatura alemana en nuestro país. Pero lo que he pretendido ha sido hacer un recorrido somero al hilo de los grandes hitos editoriales que han 
configurado el actual panorama de la literatura alemana en España y que, a lo largo de muchas décadas, han contribuido a que su presencia fuera en aumento y llegara a un público cada vez más amplio. No sabemos qué le deparará el futuro al sistema editorial amenazado ahora por la red y por el libro electrónico, y, sobre todo, por la crisis económica, pero tal vez las nuevas herramientas y la nueva orientación del mercado nos ofrezcan la posibilidad de llegar a conocer a fondo un ámbito literario por el que el lector hispano ha sentido siempre admiración y temor, y de que, de una vez por todas, la relación entre la literatura alemana y la española se afiance y deje de ser ya lo que Miguel Sáenz denominara muy acertadamente en una ocasión como "un amor imposible".

\section{Referencias bibliográficas}

Bertelmann Stiftung (ed.), Der Kulturdialog zwischen Spanien und Deutschland im Rahmen Europas. Ein Symposium am 27. Und 28. Mai 1988 in Santillana del Mar. Gütersloh: Fundación Santillana / Bertelmann Stiftung 1989.

CUÉLLAR, C., «La literatura contemporánea en lengua alemana en España: 45 años de traducciones», Estudios Filológicos Alemanes 9 (2005), 313-324.

DREYMÜLLER, C., «Anmerkungen zur Präsenz der deutschsprachigen Literatur in Spanien», en: BADER, W. / Olmos, J.I. (eds.), Die deutsch-spanischen Kulturbeziehungen im europäischen Kontext. Frankfurt: Vervuert 2004, 61-66.

HOFFMEISTER, G., España y Alemania. Madrid: Gredos 1980.

MÜLLER, B., «Die Rezeption der deutschen Literatur in Spanien», Arcadia 2:3 (1967), 257-276.

SAALBACH, M., «Missverständliches Verstehen oder verstehendes Missverständnis? Zur Rezeption zeitgenössischer deutschsprachiger Literatur in Spanien», en: RADERS, M. / SchILLING, M. L., Deutsch-spanische Literatur- und Kulturbeziehungen. Rezeptionsgeschichte / Relaciones hispano-alemanas en la literatura y la cultura. Historia de la recepción. Actas de la VII Semana de Estudios Germánicos. Madrid: Ediciones del Orto 1995, 257-266.

SÁENZ, M., «Geschichte einer unmöglichen Liebe. Die deutsche Literatur in Spanien seit 1945», en: ARNOLD, H. L. (ed.), Ansichten und Auskünfte zur deutschen Literatur nach 1945. Sonderband. Text + Kritik 1995: 168-178.

Siguan, M., «Sobre traducciones de literatura en lengua alemana a lenguas hispánicas (1976-1987)», Hispanorama 51 (1989), 80-84. 